\title{
Whey protein improves glycemia during an oral glucose tolerance test compared to vigorous- intensity aerobic exercise in young adult men
}

Ryan A Gordon ( $\sim$ rgordon002@drury.edu )

Drury University https://orcid.org/0000-0002-9452-3923

\section{Emily L Zumbro}

The University of Alabama at Birmingham Department of Medicine

\section{Todd J Castleberry}

Louisiana Technical University: Louisiana Tech University

\section{Matthew L Sokoloski}

Texas Woman's University

\section{Matthew F Brisebois}

USC Upstate: University Of South Carolina Upstate

Christopher J Irvine

Rocky Mountain College

Anthony A Duplanty

Texas Woman's University

Vic Ben-Ezra

Texas Woman's University

\section{Research Article}

Keywords: Whey, Exercise, Glucose, Insulin, Incretins, Glycemia

Posted Date: February 28th, 2022

DOI: https://doi.org/10.21203/rs.3.rs-1362627/v1

License: (1) (1) This work is licensed under a Creative Commons Attribution 4.0 International License. Read Full License 


\section{Abstract}

Background: Both aerobic exercise and whey protein can improve glucose regulation. The purpose of this study was to investigate how a single bout of vigorous-intensity aerobic exercise and whey protein, independently, as well as when combined, influence glycemia during an oral glucose tolerance test in sedentary, young men.

Methods: Healthy males $(n=11)$ completed four randomized trials: no exercise/no whey protein $(\mathrm{R})$; exercise (EX; walking at $70 \% \mathrm{VO}_{2 \max }$ for $60 \mathrm{~min}$ ); $50 \mathrm{~g}$ of whey protein (W); and exercise combined with $50 \mathrm{~g}$ of whey protein (EXW). Each trial included a $75 \mathrm{~g}$ oral glucose tolerance test (OGTT) that was completed after an overnight fast, and blood samples were collected over a two-hour period during the OGTT. For EX and EXW, the exercise bout was performed the evening before the OGTT. Additionally, for W and EXW, the $50 \mathrm{~g}$ of whey protein was consumed as a preload 30 minutes prior to the OGTT. Plasma samples were analyzed for glucose, insulin, C-peptide, glucagon, gastric inhibitory peptide (GIP) and glucagon like peptide 1 (GLP-1), and postprandial incremental area under the curve (iAUC) was calculated for each.

Results: Glucose iAUC was reduced during W $(-32.9 \pm 22.3 \mathrm{mmol} / \mathrm{L})$ compared to R $(122.7 \pm 29.8 \mathrm{mmol} / \mathrm{L}$; $p<0.01)$ and EX $(154.3 \pm 29.2 \mathrm{mmol} / \mathrm{L} ; p<0.01)$. Similarly, glucose iAUC was reduced for EXW $(17.4 \pm$ $28.9 \mathrm{mmol} / \mathrm{L})$ compared to $\mathrm{R}$ and $\mathrm{EX}(p<0.01$ for both). There were no differences in iAUC for insulin, Cpeptide, GIP, GLP-1, and glucagon between the four trials. Insulin, C-peptide, glucagon, GIP, and GLP-1 were elevated during the whey protein preload period for $\mathrm{W}$ and EXW compared to EX and $\mathrm{R}(p<0.01)$. There were no differences for insulin, C-peptide, glucagon, GIP, or GLP-1 between trials for the remaining duration of the OGTT.

Conclusions: Glucose responses during an oral glucose tolerance test were improved for W compared to EX. There were no additional improvements in glucose responses when vigorous-intensity aerobic exercise was combined with whey protein (EXW).

\section{Background}

Aerobic exercise, along with changes in diet, are primary strategies for improving blood glucose management ${ }^{1}$. Acute aerobic exercise improves glycemia through intracellular signaling within skeletal muscle ${ }^{2}$. This results in the activation of $5^{\prime}$-adenosine monophosphate-activated protein kinase (AMPK) and calcium/calmodulin-dependent protein kinase (CaMK) II, each of which influences GLUT4 translocation and expression, promoting an increase in cellular glucose uptake $\mathrm{e}^{3-5}$. This increase in glucose uptake can persist for several hours in response to a single bout of aerobic exercise ${ }^{6,7}$. Following exercise, skeletal muscle also exhibits enhanced insulin sensitivity, and this has been shown to persist for 24 to 48 hours post-exercise $e^{3,6,8-10}$. This enhanced insulin sensitivity contributes to improved glycemia while also reducing serum insulin values for 12 to 24 hours following exercise ${ }^{5,11,12}$. The intensity and duration of endurance exercise influences the magnitude of its effects on blood glucose and insulin 
sensitivity post-exercise. Many studies have attempted to determine the optimal intensity and duration of endurance exercise to maximize its effects on managing blood glucose ${ }^{11,13,14}$. Many of these studies report positive effects occur when exercise is performed for 45 to 60 minutes at moderate to vigorous intensities $\left(\geq 50 \%\right.$ of $\left.\mathrm{VO}_{2 \max }\right)$.

Similar to aerobic exercise, nutritional strategies (e.g., whey protein) are also effective for improving blood glucose. Whey protein, when consumed prior to, or with a meal, improves postprandial glycemia ${ }^{15-20}$. These improvements in postprandial glycemia are partially due to whey protein's ability to enhance insulin secretion ${ }^{21-23}$. Whey protein also stimulates the secretion of incretin hormones, glucagon-like peptide-1 (GLP-1) and gastric inhibitory peptide (GIP), which have been demonstrated to potentiate insulin secretion ${ }^{21,24-26}$. Thus, whey protein's ability to both directly and indirectly increase insulin secretion contributes to improved postprandial glycemia.

The timing of whey protein consumption is important when examining its effects on postprandial glycemia. Consuming whey protein (10 or $20 \mathrm{~g}) 30$ minutes prior to a meal (i.e., preload) has been demonstrated to slow gastric emptying and increase GLP-1 secretion ${ }^{18}$. In a similar study, Gunnerud et al. (2012) found that $9 \mathrm{~g}$ of whey protein consumed as a preload immediately prior to a mixed meal reduced postprandial plasma glucose responses (iAUC) in the first 60 minutes ${ }^{17}$. The authors attributed this effect to increased insulin secretion as a result of the whey protein consumption. In addition to timing, the dose or amount of whey protein consumed appears to influence the magnitude of its effects on blood glucose ${ }^{21}$. Several studies have demonstrated positive effects on insulin and glucose responses with higher doses $(20-55 \mathrm{~g})$ of whey protein ${ }^{19}, 23,27,28$. Our lab has previously examined how differences in the dose of whey protein can influence glycemia. We found greater improvements in glycemic responses during a $75 \mathrm{~g}$ oral glucose tolerance test (OGTT) when $30 \mathrm{~g}$ of whey protein, compared to $20 \mathrm{~g}$, was consumed 30 minutes prior to the $\mathrm{OGTT}^{29}$. Thus, whey protein's positive effects on glycemia may be dose dependent, and its effects on postprandial glycemia may be maximized when the whey protein is consumed as a preload (e.g., 30 minutes prior to a meal or beverage with a high glycemic load).

Both acute aerobic exercise and whey protein consumption improve blood glucose. Each may be effective individually, but their effects when combined are not fully understood within human subjects. Thus, the aim of this study was to investigate the individual and combined effects of a single bout of aerobic exercise and a whey protein preload on glycemic responses following an oral glucose tolerance test. When considering whey protein's ability to increase insulin secretion and exercise's effects on insulin sensitivity, we hypothesized that acute vigorous-intensity aerobic exercise $\left(70 \%\right.$ of $\mathrm{VO}_{2 \text { max }}$; performed the previous day, 12 to 14 hours before the whey protein consumption) in combination with a $50 \mathrm{~g}$ preload of whey protein prior to an oral glucose tolerance test would result in greater improvements in postprandial blood glucose responses when compared to whey protein or acute aerobic exercise alone.

\section{Methods}




\section{Study Population}

Twelve apparently healthy, sedentary males aged 18 to 44 years were recruited for this study. Participants were excluded from data collection if they were prescribed medications that would influence blood glucose concentration (sulfonylurea or metformin), blood pressure medication (thiazide diuretics, angiotensin receptor blockers, angiotensin-converting enzyme inhibitors), or answered "Yes" to any question on the Physical-Activity Readiness Questionnaire (PAR-Q+) (2016) assessment. Participation in this study also required that participants perform less than 3 days per week of exercise, or less than 150 minutes of moderate-intensity cardiorespiratory exercise for the previous three months to be classified as sedentary according to American College of Sports Medicine criteria ${ }^{30}$.

\section{Participant Screening}

Prior to data collection, this study was approved by the Institutional Review Board of Texas Woman's University (Protocol \#: 19806). In addition, prior to participation in this study, all participants were informed of the study purpose and procedures and gave their written informed consent. This study and its procedures were performed in accordance with the Declaration of Helsinki. Following explanation of the study and informed consent, a fasted (10-12 hours) blood sample was collected from an antecubital vein and analyzed for plasma glucose concentration and hemoglobin A1C. Participants with a fasted blood glucose value $\geq 100 \mathrm{mg} / \mathrm{dL}$ were excluded from the study. Throughout the duration of this study, participants were required to keep three-day diet records detailing food and drink consumed prior to each trial. Though a total of twelve participants were recruited for the study, one participant dropped out of the study due to noncompliance, resulting in eleven participants completing the study. Anthropometrics and characteristics for participants are shown in Table 1. 
Table 1

Participant Descriptive Characteristics

\begin{tabular}{|c|c|c|c|}
\hline \multirow[b]{2}{*}{ Age $(y)$} & \multicolumn{3}{|c|}{ Participants $(n=11)$} \\
\hline & 24.3 & \pm & 1.6 \\
\hline Height (cm) & 179.3 & \pm & 1.6 \\
\hline Weight (kg) & 84.3 & \pm & 6.0 \\
\hline $\mathrm{BMI}\left(\mathrm{kg} / \mathrm{m}^{2}\right)$ & 26.0 & \pm & 1.7 \\
\hline HbA1c (\%) & 5.2 & \pm & 0.1 \\
\hline Fasting Plasma Glucose (mmol/L) & 4.73 & \pm & 0.02 \\
\hline $\mathrm{VO}_{2 \max }(\mathrm{ml} / \mathrm{kg} / \mathrm{min})$ & 38.3 & \pm & 1.8 \\
\hline $\mathrm{VO}_{2 \max }(\mathrm{L} / \mathrm{min})$ & 3.1 & \pm & 0.1 \\
\hline Average Exercise HR (EX) (bpm) & 160 & \pm & 13 \\
\hline Average Exercise HR (EXW) (bpm) & 160 & \pm & 16 \\
\hline Average Exercise VO2 (EX) (L/min) & 2.2 & \pm & 0.3 \\
\hline Average Exercise VO2 (EXW) (L/min) & 2.2 & \pm & 0.5 \\
\hline Data are presented as mean $\pm \mathrm{SE}$ & & & \\
\hline
\end{tabular}

\section{Anthropometrics}

Height was measured using a stadiometer (Perspective Enterprises; Kalamazoo, MI, USA) and weight was measured to the nearest $0.1 \mathrm{~kg}$ using a digital scale (Tanita Corp.; Arlington Heights, IL, USA). From these measurements, body mass index (BMI) was calculated $\left(\mathrm{kg} / \mathrm{m}^{2}\right)$. Body composition was analyzed using a dual energy X-ray absorptiometry (DEXA) scan (General Electric Lunar DXA-Prodigy, Madison, WI, USA).

\section{Maximal Aerobic Capacity Test}

Participants performed a graded exercise test to determine their cardiorespiratory fitness. This test was performed using the Bruce Protocol on a Quinton ST65 motor driven treadmill (Quinton $\circledast$-Q Stress, Ventura, CA, USA) until exhaustion ${ }^{31}$. During this test, heart rate and rhythm was continuously monitored using a Quinton Q Stress 12-lead electrocardiograph (Welch Allyn ${ }^{\mathrm{Tm}}$, Skaneateles Falls, NY, USA). Thirtysecond averages of respiratory gas exchange were continuously collected through indirect calorimetry (ParvoMedics, Sandy, UT, USA). Attainment of maximal oxygen consumption $\left(\mathrm{VO}_{2 \max }\right)$ was determined by a plateau in $\mathrm{VO}_{2}(\leq 150 \mathrm{ml} / \mathrm{min}$ ) with an increase in workload, or a combination of achieving an RER greater than 1.1 and a maximal heart rate within $10 \mathrm{bpm}$ of age-predicted heart rate max (220-age $)^{30}$.

\section{Study Design}


Participants in this study completed four trials, and each participant performed the sequence of trials in a randomized order (see Fig. 1 for example): Trial 1; no exercise and no whey protein prior to an OGTT (R). Trial 2; 60 minutes of exercise at $70 \%$ of $\mathrm{VO}_{2 \max }$ and no whey protein prior to an OGTT (EX). Trial 3; no exercise and a $50 \mathrm{~g}$ whey protein preload consumed prior to an OGTT (W). Trial 4; 60 minutes of exercise

at $70 \%$ of $\mathrm{VO}_{2 \max }$ and a $50 \mathrm{~g}$ whey protein preload consumed prior to an OGTT (EXW). For trials in which exercise was performed, EX and EXW, the exercise session was performed 12-14 hours before the start of the OGTT for that trial (i.e., the evening before). Trials for each participant were separated by a minimum of seven days, and participants were instructed to refrain from exercise or intense physical activity between each trial. Participants were also instructed to consume a meal similar in composition to their three-day diet records the evening prior to each OGTT.

\section{Whey Protein Protocols}

Whey protein isolate (50 g; Isopure ${ }^{\circledR}$ Unflavored WPI, Nature's Best ${ }^{\mathrm{T}}{ }^{\text {, }}$, Hauppauge, NY, USA) was consumed as a preload 30 minutes prior to a $75 \mathrm{~g}$ OGTT for both $\mathrm{W}$ and EXW trials. The $50 \mathrm{~g}$ of whey protein was mixed with $250 \mathrm{ml}$ of water for both $\mathrm{W}$ and EXW trials. For R and EX trials, participants were given $250 \mathrm{ml}$ of water only as a control preload prior to their respective OGTTs.

\section{Exercise or Rest Protocols}

Exercise sessions were performed the evening prior to EX and EXW OGTTs (12-14 hours before the OGTT). These sessions consisted of walking for 60 minutes at a speed and grade that achieved $70 \%$ of the participant's $\mathrm{VO}_{2 \max } \cdot \mathrm{VO}_{2}$ was measured for 60 seconds at three separate time intervals ( $5 \mathrm{~min}, 30$ $\min$, and $60 \mathrm{~min}$ ) throughout the exercise duration to ensure the intensity was appropriate, with adjustments made to the speed or grade if necessary to maintain the target $\mathrm{VO}_{2}$. Heart rate was continuously monitored and recorded throughout the exercise session using a Polar $\mathrm{H} 9$ heart rate sensor (Polar Electro Inc., Bethpage, NY, USA).

\section{Oral Glucose Tolerance Test (OGTT) Procedures}

Participants arrived fasted (10-12 hours) to the Exercise Biochemistry Lab at Texas Woman's University between 0600 and 0800 for all OGTTs. For each OGTT, a catheter was placed in an antecubital vein by a trained phlebotomist. A blood sample $(5 \mathrm{~mL})$ was collected and analyzed for fasted glucose to verify the participant was in the fasted state. Participants then consumed either the $50 \mathrm{~g}$ of whey protein preload (W and EXW) or water as a control beverage ( $R$ and $E X)$. Participants were required to consume the whey or control beverage within five minutes. Thirty minutes after consuming the preload or water (i.e., control), a blood sample was collected. Immediately following this blood sample, participants consumed a commercial $75 \mathrm{~g}$ glucose tolerance test beverage (Trutol® Dextrose, ThermoFisher Scientific ${ }^{\mathrm{TM}}$ Inc., Waltham, MA, USA). Blood samples were then collected 15, 30, 60, 90, and 120 minutes following the consumption of the glucose tolerance test beverage (Fig. 2). A sterile saline drip was used to flush the catheter following each blood sample, with a drip rate of 1 drop per 4 seconds. Participants remained seated in a thermoneutral environment and were able to read or watch television throughout the duration of the OGTT. 


\section{Biochemical Analysis}

Blood samples were collected into $6 \mathrm{~mL}$ EDTA tubes containing a concentration of $1.25 \mathrm{mg}$ Pefabloc® of blood (Roche Diagnostics, Mannheim, Germany) and $5 \mu$ L Protease Inhibitor (EMD Millipore ${ }^{\text {TM }}$ Corporation, Billerica, MA, USA) per $\mathrm{mL}$ of blood. After collection, blood samples were immediately centrifuged at $3000 \mathrm{rpm}$ for $10 \mathrm{~min}$ at $10^{\circ} \mathrm{C}$. Plasma glucose was analyzed using a YSI 2900D glucose analyzer (Yellow Spring Inc, Yellow Springs, OH, USA). Plasma hormone concentrations of C-peptide, GIP, GLP-1, insulin, and glucagon were analyzed using a Luminex ${ }^{\mathrm{TM}}$ Human Metabolic Hormone multiplex assay (HMHEMAG-34, EMD Millipore ${ }^{\mathrm{TM}}$, Billerica, MA, USA).

\section{Statistical Analysis}

Postprandial incremental area under the curve (iAUC) was calculated from timepoints 0 to $120 \mathrm{~min}$ (OGTT) using the trapezoidal method for glucose, insulin, C-peptide, GIP, GLP-1, and glucagon. Repeated measures analysis of variance (ANOVA) was used to examine differences in iAUC for all dependent variables. A two-way repeated measures ANOVA (trial $x$ time) was also used to determine differences for glucose, insulin, glucagon, GIP, GLP-1, and C-peptide between timepoints for each trial. Greenhouse Geisser correction was used if the assumption of sphericity was violated and a Bonferroni post-hoc test was used for making comparisons when appropriate. The level of significance was set at $p \leq .05$. All statistical analyses were performed using SPSS statistical software (IBM ${ }^{\text {TM }}$ SPSS Statistics v.25, Armonk, NY, USA). All data are expressed as mean \pm standard error (SE).

\section{Results}

Fasting values for C-peptide were higher for W $(1217.7 \pm 21.8 \mathrm{pg} / \mathrm{mL})$ compared to EX $(1034.2 \pm 165.4$ $\mathrm{pg} / \mathrm{mL} ; p=0.02)$. There were no other differences for fasting variables across the four trials (Table 2 ).

Table 2

Fasting values for variables between all four trials

\begin{tabular}{|lllll|}
\hline & R & EX & W & EXW \\
\hline Glucose $(\mathrm{mmol} / \mathrm{L})$ & $4.97 \pm 0.1$ & $4.84 \pm 0.1$ & $5.01 \pm 0.2$ & $4.93 \pm 0.1$ \\
\hline Insulin $(\mathrm{pg} / \mathrm{mL})$ & $945.6 \pm 153.2$ & $833.5 \pm 149.1$ & $895.9 \pm 163.9$ & $917.9 \pm 148.7$ \\
\hline C-peptide $(\mathrm{pg} / \mathrm{mL})$ & $1235.5 \pm 230.5$ & $1034.2 \pm 165.4$ & $1217.7 \pm 201.8^{\mathrm{b}}$ & $1173.7 \pm 191.0$ \\
\hline GIP $(\mathbf{p g} / \mathrm{mL})$ & $73.6 \pm 9.7$ & $75.3 \pm 11.1$ & $66.8 \pm 7.8$ & $81.9 \pm 14.7$ \\
\hline GLP-1 $(\mathbf{p g} / \mathrm{mL})$ & $7.8 \pm 2.0$ & $6.7 \pm 0.9$ & $6.5 \pm 0.8$ & $7.9 \pm 2.7$ \\
\hline Glucagon $(\mathbf{p g} / \mathrm{mL})$ & $78.1 \pm 11.1$ & $73.2 \pm 9.2$ & $66.6 \pm 7.5$ & $76.7 \pm 10.7$ \\
\hline${ }^{b}$ Represents a significant difference compared to EX. Data are represented as mean $\pm \mathrm{SE}$ \\
\hline
\end{tabular}


No differences in glucose values were reported between timepoints for each trial (Fig. 3A). There was a main effect observed for glucose iAUC. Glucose iAUC was lower for W $(-32.9 \pm 22.3 \mathrm{mmol} / \mathrm{L})$ compared to $\mathrm{R}(122.7 \pm 29.8 \mathrm{mmol} / \mathrm{L} ; p<0.01)$ and EX $(154.3 \pm 29.2 \mathrm{mmol} / \mathrm{L} ; p<0.01 ;$ Fig. 3B). Additionally, glucose iAUC was lower for EXW $(17.4 \pm 28.9 \mathrm{mmol} / \mathrm{L})$ compared to $\mathrm{R}(p<0.01)$ and EX $(p<0.01)$. There were no differences between $\mathrm{W}$ and EXW.

\section{Insulin and C-peptide}

As shown in Fig. 4A, insulin was elevated during the 30-minute whey protein preload period (timepoints 30 to 0$)$ for both $W(1742.0 \pm 238.0 \mathrm{pg} / \mathrm{mL})$ and EXW $(1791.4 \pm 292.8 \mathrm{pg} / \mathrm{mL})$ compared to $\mathrm{R}(891.6 \pm$ $165.2 \mathrm{pg} / \mathrm{mL} ; p<0.01)$ and $\mathrm{EX}(789.1 \pm 147.2 \mathrm{pg} / \mathrm{mL} ; p<0.01)$. After consuming the $75 \mathrm{~g}$ glucose tolerance test drink (timepoint 0 from Fig. 2), there were no differences in insulin iAUC between the four trials. C-peptide response was similar to insulin, with a significant increase between timepoints -30 to 0 for W $(1979.0 \pm 260.1 \mathrm{pg} / \mathrm{mL} ; p=0.02)$ and EXW $(1984.4 \pm 273.6 \mathrm{pg} / \mathrm{mL} ; \mathrm{p}<0.01)$ compared to EX (982.8 $\pm 160.6 \mathrm{pg} / \mathrm{mL})$ and $\mathrm{R}(1183.7 \pm 215.6 \mathrm{pg} / \mathrm{mL} ; p<0.01 ;$ Fig. $5 \mathrm{~A})$. No differences were observed for Cpeptide iAUC between the four trials (Fig. 5B).

\section{Incretins and Glucagon}

As shown in Fig. 6A, GIP was elevated during the 30-minute whey protein preload period (timepoints - 30 to 0$)$ for $\mathrm{W}(169.5 \pm 19.5 \mathrm{pg} / \mathrm{mL})$ and EXW $(179.3 \pm 11.7 \mathrm{pg} / \mathrm{mL})$ compared to $\mathrm{R}(60.9 \pm 8.1 \mathrm{pg} / \mathrm{mL} ; p<$ $0.01)$ and $E X(66.1 \pm 7.6 \mathrm{pg} / \mathrm{mL} ; p<0.01)$. Similarly, GLP-1 was elevated during the 30 -minute whey protein period (timepoints -30 to 0$)$ for $\mathrm{W}(15.5 \pm 2.5 \mathrm{pg} / \mathrm{mL})$ compared to $\mathrm{EX}(5.3 \pm 1.4 \mathrm{pg} / \mathrm{mLI} p<0.01)$, while EXW was increased during this period compared to $\mathrm{R}(6.2 \pm 1.8 \mathrm{pg} / \mathrm{mL} ; p<0.01)$ and $\mathrm{EX}(p<0.01$; Fig. 6C.) There were no significant differences in iAUC between the four trials for GIP (Fig. 6B) or GLP-1 (Fig. 6D).

Glucagon was elevated during the 30-minute whey protein preload period (timepoints - 30 to 0 ) for both $\mathrm{W}(140.9 \pm 11.6 \mathrm{pg} / \mathrm{mL})$ and EXW $(163.5 \pm 14.9 \mathrm{pg} / \mathrm{mL})$ compared to $\mathrm{R}(67.7 \pm 10.3 ; p<0.01)$ and EX $(69.2 \pm 11.2 \mathrm{pg} / \mathrm{mL} ; p<0.01 ; \mathrm{Fig} .7 \mathrm{~A})$. There were no significant differences in iAUC between the four trials for glucagon (Fig. 7B).

\section{Discussion}

Here, we investigated how a single bout of vigorous-intensity aerobic exercise and whey protein consumption, independent of each other and combined, influence glycemic responses to a $75 \mathrm{~g}$ OGTT in young adult men. This study is novel as it is one of few studies that has investigated their combined effects on glycemia. Moreover, this study utilized a unique time frame (exercise and whey protein separated by 12-14 hours) for investigating how aerobic exercise and whey protein interact to affect glycemia.

We found the combination of vigorous-intensity aerobic exercise and whey protein (EXW) reduced glucose iAUC values during a two-hour OGTT compared to exercise alone (EX). This effect on glucose 
iAUC was also observed when whey protein was consumed independent of exercise (W). Importantly, these effects on glucose iAUC were achieved without significant increases in insulin iAUC during $W$ or EXW compared to R or EX. Despite these effects on glucose and insulin iAUC, there were no differences in C-peptide, glucagon, GIP, or GLP-1 iAUC values throughout the two-hour OGTT between the four trials.

\section{Glucose/Insulin}

Our results for glucose iAUC when $50 \mathrm{~g}$ of whey protein was consumed as a preload (W and EXW) are similar to other studies that have investigated whey protein's effects at higher doses $(50 \mathrm{~g})$ on glycemia 27 , 28 . However, these effects on glycemia were not observed when exercise was performed independent of whey protein (EX). The improvements in glucose iAUC for W and EXW were accompanied by increases in insulin responses 30 minutes after whey protein consumption (-30 to 0 timepoint), though insulin iAUC was not different between the four trials. The changes observed for W and EXW may be attributed to this acute spike in insulin following the whey protein preload, which was then followed by a more normalized insulin response throughout the remaining duration of the OGTT.

Whey protein's positive effects on glucose management are exemplified by our results for EX. EX had similar glucose responses to $R$ at each individual timepoint throughout the OGTT (Fig. 3A), and glucose iAUC values for EX were higher than R (Fig. 3B). Our results for EX are similar to previous studies that have investigated the influence of acute aerobic exercise on glycemia ${ }^{32,33}$. Though overall insulin responses to the OGTT were lowest for EX, there were no significant effects on insulin iAUC or differences between timepoints compared to the other three trials. We found this surprising, as several studies have reported improvements in insulin responses to aerobic exercise ${ }^{34,35}$. Our results for EX may be explained most clearly by the fact that the exercise was performed 12-14 hours prior to the OGTT, potentially diminishing exercise's insulin sensitizing effects. As the participants in this study were relatively young, healthy men, it indicates higher intensities and/or durations may be necessary to sustain post-exerciseinduced improvements in insulin sensitivity over longer durations (12+hours) in this population. Overall, our findings for $\mathrm{W}$ in relation to EX indicate whey protein has important applications for managing glycemia. As there were no further improvements with EXW compared to W, our results suggest whey protein may have a larger influence on acute glycemia compared to exercise in this population.

\section{GIP, GLP-1, and Glucagon}

The incretins, GIP and GLP-1, have important roles in promoting insulin secretion and glucose management, with some suggesting the incretins account for $50-70 \%$ of insulin secretion following a meal ${ }^{36}$. In comparison to previous literature on this topic, Ma et al. (2009) reported whey protein had stimulatory effects on both GIP and GLP-1 at doses similar to those used in this study ${ }^{27}$. We found no differences in iAUC for GIP or GLP-1 between the four trials. However, we observed significant increases in GIP and GLP-1 for both W and EXW during the whey protein preload prior to the OGTT (timepoints - 30 to 0). These increases in GIP and GLP-1 for W and EXW coincide with observed changes in insulin, which likely contributed to the improvements in glucose iAUC for these trials. Specifically, we speculate that this 
brief increase in GIP and GLP-1 following whey protein consumption could have potentiated insulin secretion, contributing to the observed glucose responses for W and EXW. Our findings for GIP and GLP-1 following whey protein consumption is similar to results from Jakubowicz et al. (2014). Using a similar study design, they found increases in GLP-1 30 minutes after consuming whey protein, though also reporting GLP-1 continued to increase following a high glycemic-index meal ${ }^{15}$.

In addition to their effects on insulin secretion, the incretin hormones have regulatory effects on glucagon. Specifically, GIP can enhance glucagon secretion, while GLP-1 has been shown to inhibit glucagon secretion ${ }^{25,37}$. We found no significant differences in glucagon iAUC between the four trials. However, similar to GIP and GLP-1, when examining glucagon's response prior to the OGTT (timepoints 30 to 0 ), glucagon was elevated for both W and EXW during this time period. Considering GIP and GLP-1's opposing effects on glucagon, it appears GIP may have a stronger regulatory effect on glucagon than GLP-1, contributing to the observed increase in glucagon following the whey protein preload. Comparing responses for glucose, insulin, and glucagon throughout the OGTT, an interesting pattern emerges whereby insulin and glucagon are elevated similarly for $W$ and EXW with respect to $R$ and EX. Specifically, for $W$ and EXW, glucagon peaked after the whey protein preload period (timepoints - 30 to 0 ) but remained elevated, albeit to a lesser extent, throughout the duration of the OGTT. Insulin response was similar, increasing after the whey protein was consumed, though its concentration peaked after the OGTT commenced (30-minute timepoint). What is interesting is that despite these similar, yet opposing, responses between glucagon and insulin, glucose responses for W and EXW were relatively stagnant, and even decreased below baseline glucose values throughout the OGTT. This observed effect appears to be exclusive to whey protein consumption as well, as glucagon decreased for EX during the OGTT. What this dynamic interaction between glucagon and insulin means in the context of glycemia regulation when whey protein is consumed, as well as how GIP and GLP-1 may influence these observed effects requires further exploration.

\section{Limitations}

This study and its results have some limitations that should be considered for prospective investigations. For instance, the participants in this study were limited to young, adult men. As the scope of this study is largely relevant to the management of metabolic disease (i.e., type II diabetes), future studies should consider exploring the relationship between whey protein and exercise in individuals with metabolic disease. Additionally, several studies have explored whey protein's effects on glycemia at varied doses (e.g., $20 \mathrm{~g}$ or $30 \mathrm{~g}$ ). Based upon our findings in this study at $50 \mathrm{~g}$ of whey protein, it may be worth exploring how varied doses of whey protein, in conjunction with vigorous-intensity aerobic exercise, may influence glycemia. Lastly, as participants in this study walked at a vigorous intensity for the exercise intervention, our results are limited to this specific type of exercise. It may be worth investigating how different modes of exercise incorporating mechanical loading (e.g., resistance exercise, or aerobic and resistance exercise combined) when combined with whey protein may influence glycemia. 


\section{Conclusions}

We found whey protein consumed independent of performing exercise improved glucose responses to a $75 \mathrm{~g}$ OGTT. This improvement was also observed when whey protein and vigorous-intensity aerobic exercise were combined, but this effect was lost when exercise was performed alone. These results provide information for how vigorous-intensity aerobic exercise and whey protein individually, and when combined, positively affect glycemia. This study addressed how the timing between exercise and whey protein may influence these responses as well, which is important when considering the real-world application of these results. To summarize, our results highlight the short-term effectiveness of whey protein, independently and in combination with aerobic exercise, for improving glycemia.

\section{Abbreviations}

DEXA Dual energy X-ray absorptiometry

EX Exercise/no whey protein

EXW Exercise/whey protein

GIP Gastric inhibitory peptide

GLP-1 Glucagon-like peptide 1

¡AUC Incremental area under the curve

OGTT Oral glucose tolerance test

R No exercise/no whey protein

W No exercise, whey protein

\section{Declarations}

\section{Acknowledgements}

The authors would like to thank the subjects who participated in this study.

\section{Authors' contributions}

TJC and VB conceived and designed research. RAG, ELZ, TJC, MLS, MFB, and CJI conducted experiments. RAG, ELZ, and TJC analyzed data. RAG, ELZ, and MLS drafted the manuscript. MFB, AAD, and VB critically revised the manuscript. All authors read and approved the manuscript.

\section{Funding}


Funding used for the collection and analysis of data was supported in part by a Texas American College of Sports Medicine Student Research Development Award (SRDA). ELZ is currently supported by a T32 Postdoctoral Award from the National Institutes of Health (T32HL007457). The content is solely the responsibility of the authors and does not necessarily represent the official views of the National Institutes of Health.

\section{Availability of data and materials}

The datasets used and/or analyzed in this current study are available from the corresponding author on reasonable request.

\section{Ethics approval and consent to participate}

This study includes human participants and data, and prior to data collection, this study was approved by the Institutional Review Board of Texas Woman's University (Protocol \#: 19806). In addition, prior to participation in this study, all participants were informed of the study purpose and procedures and gave their written informed consent. This study and its procedures were performed in accordance with the Declaration of Helsinki.

\section{Consent for publication}

Not applicable

\section{Competing interests}

The authors declare no conflicts of interest in regard to the research, authorship, and/or publication of this article.

\section{References}

1. Kirwan JP, Sacks J, Nieuwoudt S. The essential role of exercise in the management of type 2 diabetes. Cleveland Clinic Journal of Medicine. 2017;84(7 Suppl 1):S15- S21. https://doi.org/10.3949/ccjm.84.s1.03

2. McGarrah RW, Slentz CA, Kraus WE. The effect of vigorous- versus moderate-intensity aerobic exercise on insulin action. Current Cardiology Reports. 2016;18(12):117. https://doi.org/10.1007/s11886-016-0797-7

3. Lehnen, A., Angelis, K. D., Markoski, M. M., \& Schaan, B. D. A. (2012). Changes in the GLUT4 expression by acute exercise, exercise training and detraining in experimental models. Journal of Diabetes Metabolism S, 10(2). http://dx.doi.org/10.4172/2155-6156.S10-002

4. Richter, E. A., \& Hargreaves, M. (2013). Exercise, GLUT4, and skeletal muscle glucose uptake. Physiological Reviews. https://doi.org/10.1152/physrev.00038.2012 
5. Douen, A. G., Ramlal, T., Rastogi, S., Bilan, P. J., Cartee, G. D., Vranic, M., ... \& Klip, A. (1990). Exercise induces recruitment of the "insulin-responsive glucose transporter". Evidence for distinct intracellular insulin-and exercise-recruitable transporter pools in skeletal muscle. Journal of Biological Chemistry, 265(23), 13427-13430. https://doi:10.1016/S0021-9258(18)77362-6

6. Maarbjerg, S. J., Sylow, L., \& Richter, E. A. (2011). Current understanding of increased insulin sensitivity after exercise-emerging candidates. Acta Physiologica, 202(3), 323-335. https://doi.org/10.1111/j.1748-1716.2011.02267.x

7. Jensen, T. E., \& Richter, E. A. (2012). Regulation of glucose and glycogen metabolism during and after exercise. The Journal of Physiology, 590(5), 1069-1076.

https://doi.org/10.1113/jphysiol.2011.224972

8. Kjøbsted, R., Munk-Hansen, N., Birk, J. B., Foretz, M., Viollet, B., Björnholm, M., Zierath, J., Treeback, J., \& Wojtaszewski, J. F. (2017). Enhanced muscle insulin sensitivity after contraction/exercise is mediated by AMPK. Diabetes, 66(3), 598-612. https://doi.org/10.2337/db16-0530

9. Cartee, G. D. (2015). Mechanisms for greater insulin-stimulated glucose uptake in normal and insulinresistant skeletal muscle after acute exercise. American Journal of Physiology-Endocrinology and Metabolism, 309(12), E949-E959. https://doi.org/10.1152/ajpendo.00416.2015

10. Steenberg, D. E., Jørgensen, N. B., Birk, J. B., Sjøberg, K. A., Kiens, B., Richter, E. A., \& Wojtaszewski, J. F. (2019). Exercise training reduces the insulin-sensitizing effect of a single bout of exercise in human skeletal muscle. The Journal of Physiology, 597(1), 89-103.

https://doi.org/10.1113/JP276735

11. Hübinger, A., Franzen, A., \& Gries, F. A. (1987). Hormonal and metabolic response to physical exercise in hyperinsulinemic and non-hyperinsulinemic type 2 diabetics. Diabetes Research, 4(2), 57-61.

12. Jankowski, C., Ben-Ezra, V., Kendrick, K., Morriss, R., \& Nichols, D. (1999). Effect of exercise on postprandial insulin responses in Mexican American and non- Hispanic women. Metabolism, 48(8), 971-977. https://doi.org/10.1016/S0026-0495(99)90192-0

13. Rogers, M., Yamamoto, C., King, D., Hagberg, J., Ehsani, A., \& Holloszy, J. (1988). Improvement in glucose tolerance after $1 \mathrm{wk}$ of exercise in patients with mild NIDDM. Diabetes Care, 11(8), 613-618. https://doi.org/10.2337/diacare.11.8.613

14. Sylow, L., Kleinert, M., Richter, E. A., \& Jensen, T. E. (2017). Exercise-stimulated glucose uptakeregulation and implications for glycaemic control. Nature Reviews Endocrinology, 13(3), 133-148. https://doi.org/10.1038/nrendo.2016.162

15. Jakubowicz, D., Froy, O., Ahrén, B., Boaz, M., Landau, Z., Bar-Dayan, Y., Ganz, T., Barnea, M., \& Wainstein, J. (2014). Incretin, insulinotropic and glucose-lowering effects of whey protein pre-load in type 2 diabetes: a randomised clinical trial. Diabetologia, 57(9), 1807-1811. https://doi.org/10.1007/s00125-014-3305-x

16. Gunnerud, U. J., Östman, E. M., \& Björck, I. M. E. (2013). Effects of whey proteins on glycaemia and insulinaemia to an oral glucose load in healthy adults; a dose- response study. European Journal of Clinical Nutrition, 67(7), 749-753. https://doi.org/10.1038/ejcn.2013.88 
17. Gunnerud, U. J., Heinzle, C., Holst, J. J., Östman, E. M., \& Björck, I. M. (2012). Effects of pre- meal drinks with protein and amino acids on glycemic and metabolic responses at a subsequent composite meal. Plos One, 7(9): e44731. https://doi.org/10.1371/journal.pone.0044731

18. Akhavan, T., Luhovyy, B. L., Panahi, S., Kubant, R., Brown, P. H., \& Anderson, G. H. (2014). Mechanism of action of pre-meal consumption of whey protein on glycemic control in young adults. The Journal of Nutritional Biochemistry, 25(1), 36-43. https://doi.org/10.1016/j.jnutbio.2013.08.012

19. Petersen, B. L., Ward, L. S., Bastian, E. D., Jenkins, A. L., Campbell, J., \& Vuksan, V. (2009). A whey protein supplement decreases post-prandial glycemia. Nutrition Journal, 8(1), 1-5. https://doi.org/10.1186/1475-2891-8-47

20. Bowen, J., Noakes, M., Trenerry, C., \& Clifton, P. M. (2006). Energy intake, ghrelin, and cholecystokinin after different carbohydrate and protein preloads in overweight men. The Journal of Clinical Endocrinology \& Metabolism, 91(4), 1477-1483. https://doi.org/10.1210/jc.2005-1856

21. Mignone, L. E., Wu, T., Horowitz, M., \& Rayner, C. K. (2015). Whey protein: The "whey" forward for treatment of type 2 diabetes?. World Journal of Diabetes, 6(14), 1274.

https://dx.doi.org/10.4239\%2Fwjd.v6.i14.1274

22. Stevenson, E. J., \& Allerton, D. M. (2018). The role of whey protein in postprandial glycaemic control. Proceedings of the Nutrition Society, 77(1), 42-51. https://doi:10.1017/S0029665117002002

23. Akhavan, T., Luhovyy, B. L., Brown, P. H., Cho, C. E., \& Anderson, G. H. (2010). Effect of premeal consumption of whey protein and its hydrolysate on food intake and postmeal glycemia and insulin responses in young adults. The American Journal of Clinical Nutrition, 91(4), 966-975. https://doi.org/10.3945/ajcn.2009.28406

24. Nilsson, M., Holst, J. J., \& Björck, I. M. (2007). Metabolic effects of amino acid mixtures and whey protein in healthy subjects: studies using glucose-equivalent drinks. The American Journal of Clinical Nutrition, 85(4), 996-1004. https://doi.org/10.1093/ajcn/85.4.996

25. Frid, A. H., Nilsson, M., Holst, J. J., \& Björck, I. M. (2005). Effect of whey on blood glucose and insulin responses to composite breakfast and lunch meals in type 2 diabetic subjects. The American Journal of Clinical Nutrition, 82(1), 69-75. https://doi.org/10.1093/ajcn/82.1.69

26. Adams, R. L., \& Broughton, K. S. (2016). Insulinotropic effects of whey: mechanisms of action, recent clinical trials, and clinical applications. Annals of Nutrition and Metabolism, 69(1), 56-63. https://doi.org/10.1159/000448665

27. Ma, J., Stevens, J. E., Cukier, K., Maddox, A. F., Wishart, J. M., Jones, K. L., Clifton, P. M., Horowitz, M., \& Rayner, C. K. (2009). Effects of a protein preload on gastric emptying, glycemia, and gut hormones after a carbohydrate meal in diet- controlled type 2 diabetes. Diabetes Care, 32(9), 1600-1602. https://doi.org/10.2337/dc09-0723

28. Hoefle, A. S., Bangert, A. M., Stamfort, A., Gedrich, K., Rist, M. J., Lee, Y. M., ... \& Daniel, H. (2015). Metabolic responses of healthy or prediabetic adults to bovine whey protein and sodium caseinate do not differ. The Journal of Nutrition, 145(3), 467-475. https://doi.org/10.3945/jn.114.199190 
29. Castleberry, T., Irvine, C., Gordon, R., Brisebois, M., Deemer, S., Henderson, A., Sokoloski, M., \& BenEzra, V. (2020). The dose effect of whey protein on glycemic control in adults with insulin resistance. International Journal of Food Science and Biotechnology, 5(4), 62-67.

https://doi.org/10.11648/j.jjfsb.20200504.12

30. Liguori, G., \& American College of Sports Medicine. (2020). ACSM's guidelines for exercise testing and prescription. Lippincott Williams \& Wilkins.

31. Fletcher, G. F., Balady, G. J., Amsterdam, E. A., Chaitman, B., Eckel, R., Fleg, J., Froelicher, V. F., Leon, A. S., Ileana, L. P., Rodney, R., Simons-Morton, D. A., Williams, M. A., \& Bazzarre, T. (2001). Exercise standards for testing and training: a statement for healthcare professionals from the American Heart Association. Circulation, 104(14), 1694-1740. https://doi.org/10.1161/hc3901.095960

32. Cononie, C. C., Goldberg, A. P., Rogus, E., \& Hagberg, J. M. (1994). Seven consecutive days of exercise lowers plasma insulin responses to an oral glucose challenge in sedentary elderly. Journal of the American Geriatrics Society, 42(4), 394-398. https://doi.org/10.1111/j.1532-5415.1994.tb07487.x

33. Jankowski, C. M., Ben-Ezra, V., Gozansky, W. S., \& Scheaffer, S. E. (2004). Effects of oral contraceptives on glucoregulatory responses to exercise. Metabolism, 53(3), 348-352. https://doi.org/10.1016/j.metabol.2003.10.024

34. Henriksen, E. J. (2002). Invited review: Effects of acute exercise and exercise training on insulin resistance. Journal of Applied Physiology, 93(2), 788-796.

https://doi.org/10.1152/japplphysiol.01219.2001

35. Frampton, J., Cobbold, B., Nozdrin, M., Oo, H. T., Wilson, H., Murphy, K. G., Frost, G., \& Chambers, E. S. (2021). The effect of a single bout of continuous aerobic exercise on glucose, insulin and glucagon concentrations compared to resting conditions in healthy adults: A systematic review, meta-analysis and meta- regression. Sports Medicine, 1-18. https://doi.org/10.1007/s40279-021-01473-2

36. Holst, J. J., \& Deacon, C. F. (2013). Is there a place for incretin therapies in obesity and prediabetes?. Trends in Endocrinology \& Metabolism, 24(3), 145-152. https://doi.org/10.1016/j.tem.2013.01.004

37. Holst, J. J., Christensen, M., Lund, A., De Heer, J., Svendsen, B., Kielgast, U., \& Knop, F. K. (2011). Regulation of glucagon secretion by incretins. Diabetes, Obesity and Metabolism, 13, 89-94. https://doi.org/10.1111/j.1463-1326.2011.01452.x

\section{Figures}

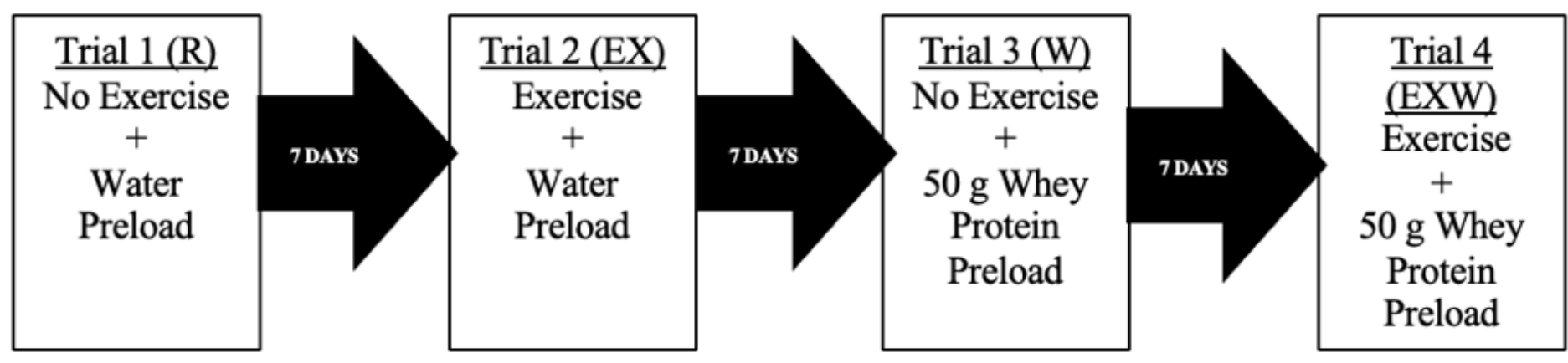


Figure 1

Representation of the randomly sequenced trials performed by participants

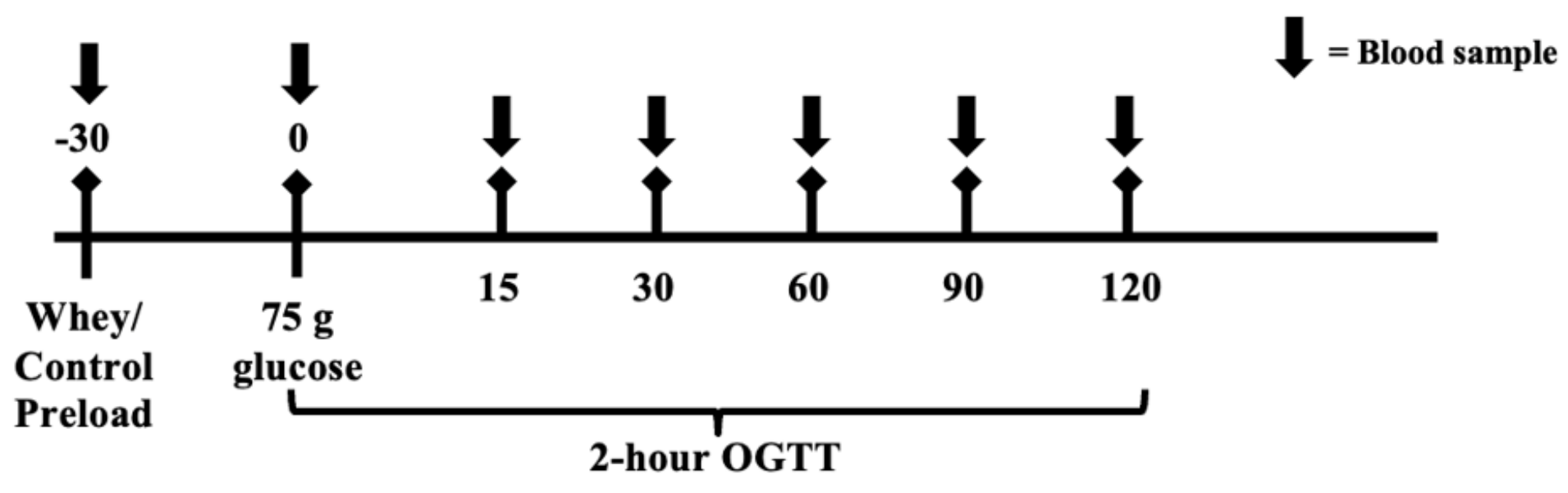

Figure 2

Timeline of preload beverage consumption and blood sample collection throughout the OGTT for each trial

Figure 3

A) Blood glucose response ( $\mathrm{mmol} / \mathrm{L}$ ) prior to and during a two-hour oral glucose tolerance test between each trial. B) Blood glucose iAUC ( $\mathrm{mmol} / \mathrm{L}$ ) during the two-hour oral glucose tolerance test between each trial. R; no exercise, no whey protein, EX; exercise, no whey protein, W; no exercise, whey protein, EXW; exercise, whey protein. ${ }^{a}$ Represents a significant difference compared to R. ${ }^{b}$ Represents a significant difference compared to EX.

A)

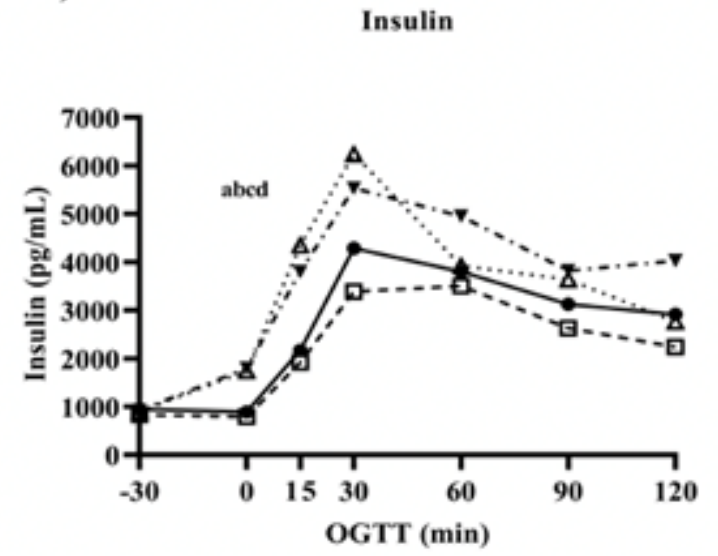

B)

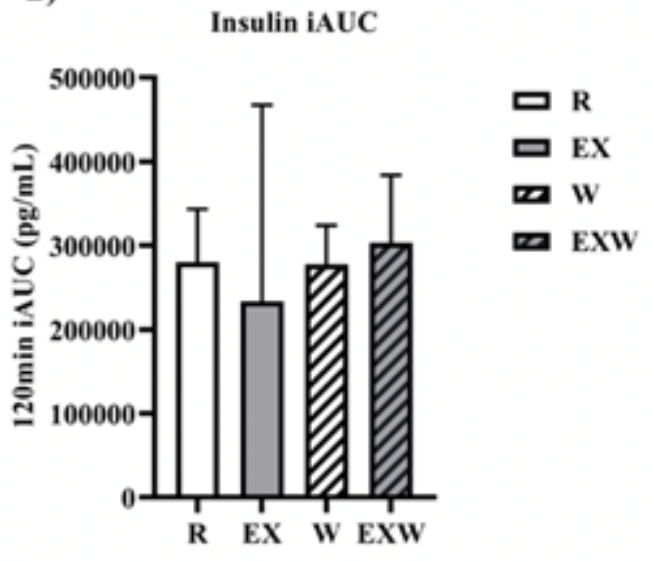




\section{Figure 4}

A) Insulin response $(\mathrm{pg} / \mathrm{mL})$ prior to and during a two-hour oral glucose tolerance test between each trial.

B) Insulin iAUC $(\mathrm{pg} / \mathrm{mL})$ during the two-hour oral glucose tolerance test between each trial. R; no exercise, no whey protein, EX; exercise, no whey protein, W; no exercise, whey protein, EXW; exercise, whey protein. ${ }^{a}$ and ${ }^{b}$ represent significant differences for $W$ compared to $R$ and $E X$ between timepoints -30 to 0 , respectively. ${ }^{c}$ and ${ }^{d}$ represent significant differences for EXW compared to $R$ and EX between timepoints -30 to 0 , respectively.
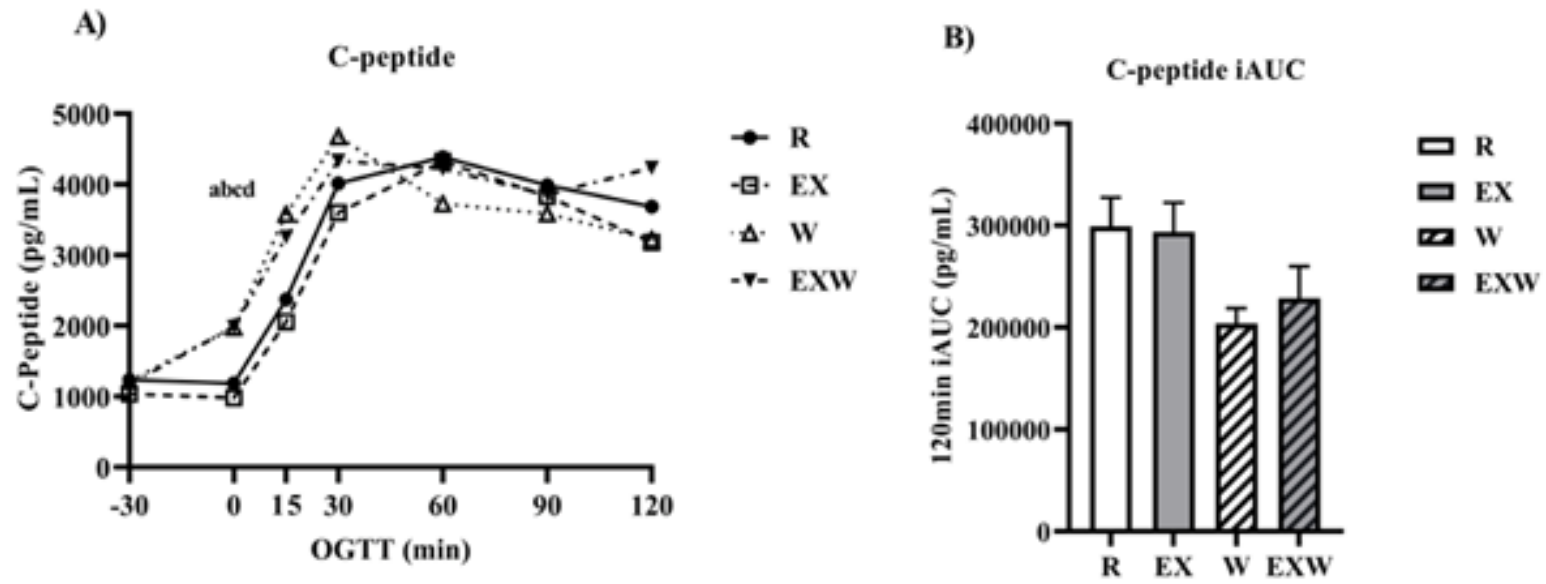

\section{Figure 5}

A) C-peptide response $(\mathrm{pg} / \mathrm{mL})$ prior to and during a two-hour oral glucose tolerance test between each trial. B) C-peptide iAUC $(\mathrm{pg} / \mathrm{mL})$ during the two-hour oral glucose tolerance test between each trial. R; no exercise, no whey protein, EX; exercise, no whey protein, W; no exercise, whey protein, EXW; exercise, whey protein. ${ }^{a}$ and ${ }^{b}$ represent significant differences for $W$ compared to $R$ and $E X$ between timepoints -30 to 0 , respectively. ${ }^{c}$ and ${ }^{d}$ represent significant differences for EXW compared to $\mathrm{R}$ and EX between timepoints -30 to 0 , respectively. 
A)

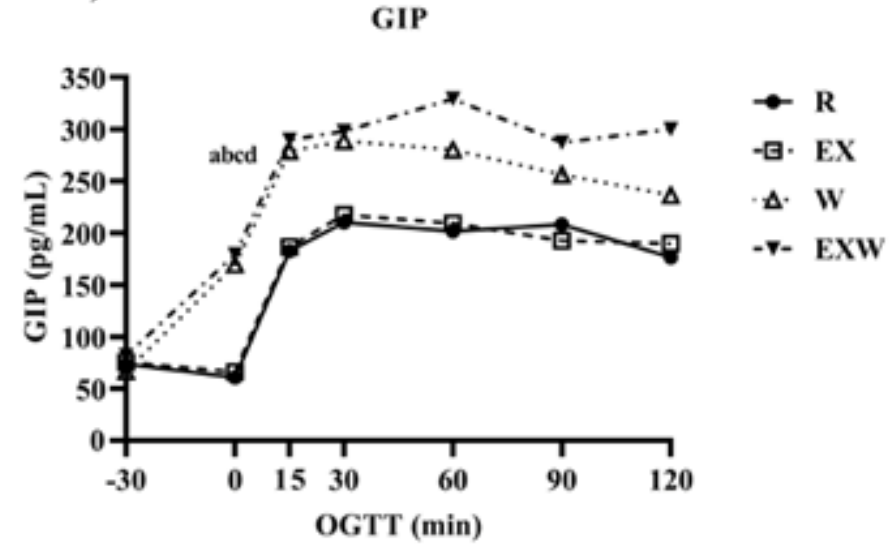

C)

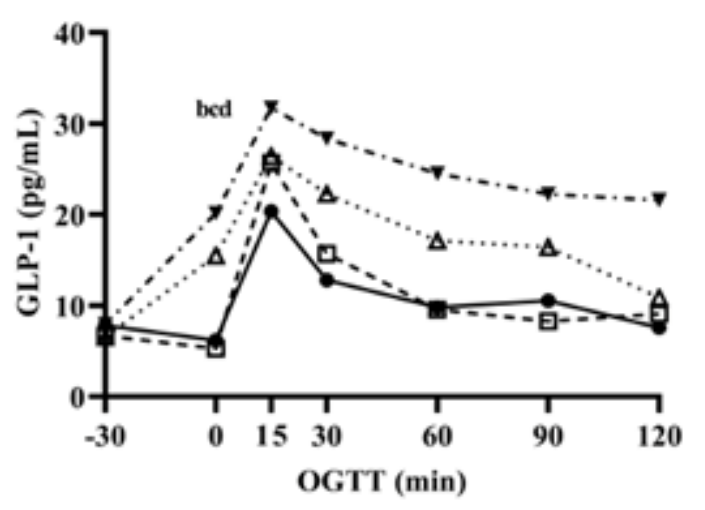

B)

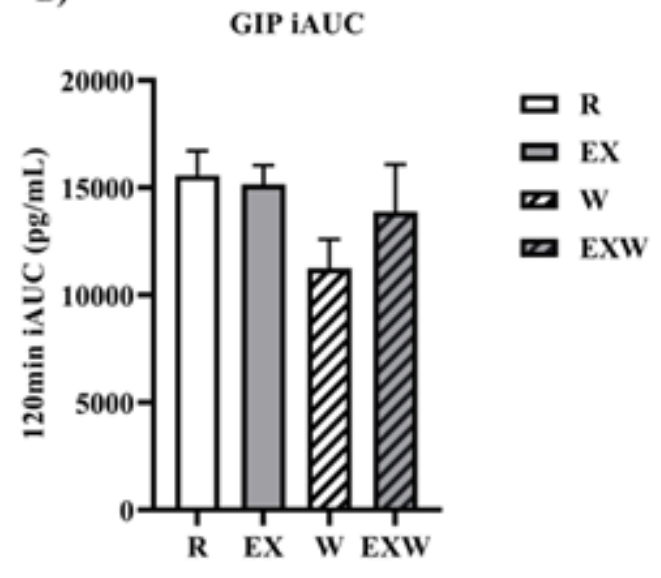

D)

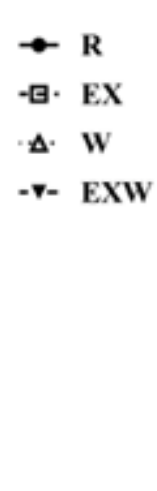

\section{GLP-1 iAUC}

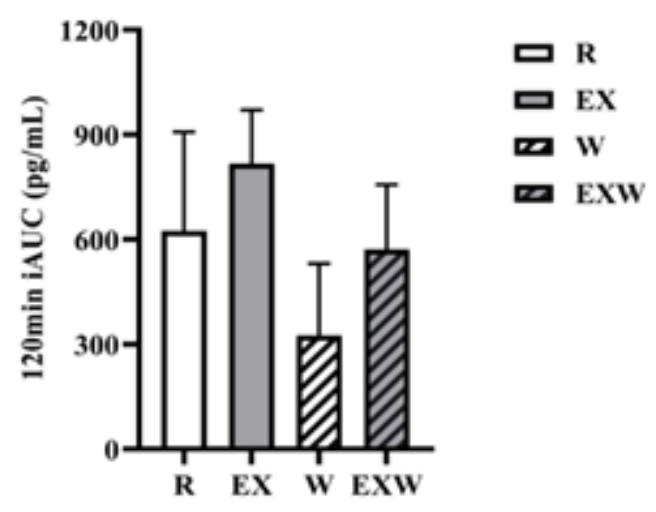

Figure 6

A) GIP response (pg/mL) prior to and during a two-hour oral glucose tolerance test between each trial. B) GIP iAUC (pg/mL) during the two-hour oral glucose tolerance test between each trial. C) GLP-1 response $(\mathrm{pg} / \mathrm{mL})$ prior to and during a two-hour oral glucose tolerance test between each trial. D) GLP-1 iAUC $(\mathrm{pg} / \mathrm{mL})$ during the two-hour oral glucose tolerance test between each trial. R; no exercise, no whey protein, EX; exercise, no whey protein, W; no exercise, whey protein, EXW; exercise, whey protein. ${ }^{a}$ and ${ }^{b}$ represent significant differences for $\mathrm{W}$ compared to $\mathrm{R}$ and $\mathrm{EX}$ between timepoints -30 to 0 , respectively. ${ }^{\mathrm{C}}$ and ${ }^{d}$ represent significant differences for EXW compared to $R$ and EX between timepoints -30 to 0 , respectively. 
A)

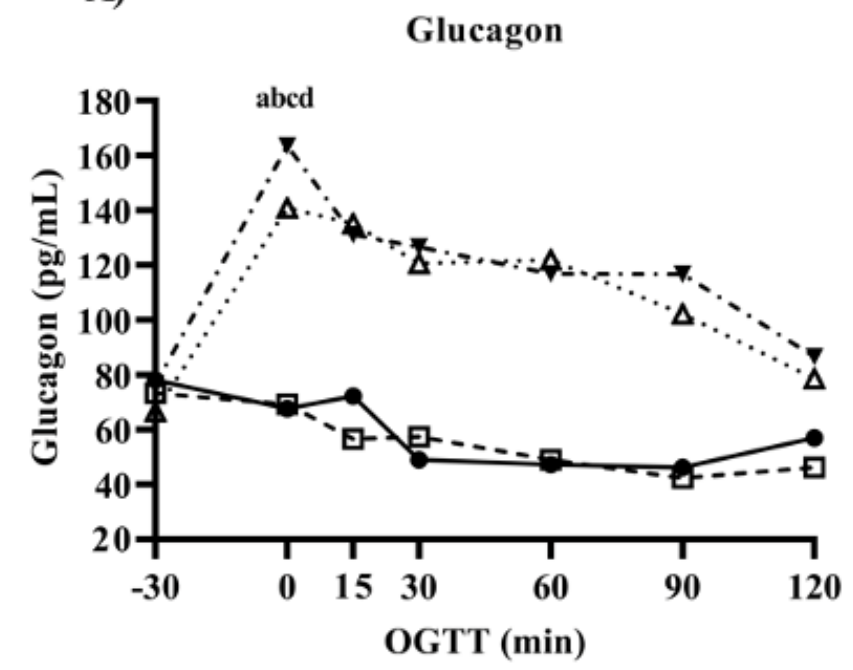

B)

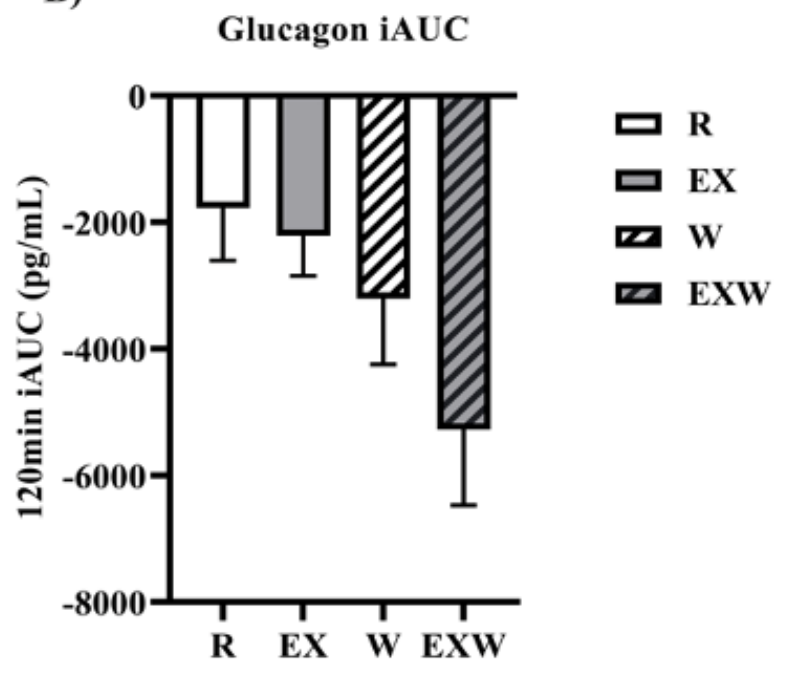

Figure 7

A) Glucagon response ( $\mathrm{pg} / \mathrm{mL})$ prior to and during a two-hour oral glucose tolerance test between each trial. B) Glucagon iAUC ( $\mathrm{pg} / \mathrm{mL}$ ) during the two-hour oral glucose tolerance test between each trial. R; no exercise, no whey protein, EX; exercise, no whey protein, W; no exercise, whey protein, EXW; exercise, whey protein. ${ }^{a}$ and ${ }^{b}$ represent significant differences for $W$ compared to $R$ and $E X$ between timepoints -30 to 0 , respectively. ${ }^{c}$ and ${ }^{d}$ represent significant differences for EXW compared to $R$ and EX between timepoints -30 to 0 , respectively. 